\title{
Friction influence on the AA6060 aluminium alloy formability
}

\author{
Costanzo Bellini, Gillo Giuliano, Luca Sorrentino \\ University of Cassino and Southern Lazio, Department of Civil and Mechanical Engineering, Italy \\ costanzo.bellini@unicas.it, http:/ /orcid.org/0000-0003-4804-6588 \\ gillo.giuliano@unicas.it \\ luca.sorrentino@unicas.it, bttp://orcid.org/0000-0002-5278-7357
}

ABSTRACT. Using a finite element calculation code, this work analyses the influence of friction during a stamping test conducted on the AA6060 aluminium-based alloy. The study focuses on phenomena happening when the sheet necking appears. This condition, based on the Hill's localized necking theory and the Swift's diffuse necking theory, is dependent on the material hardening index. This work shows that the punch stroke at the necking condition point is maximum when the main strain measured on the sheet surface is unbalanced and close to a balanced biaxial tension condition.

KEYwORDS. AA6060 aluminium alloy; Forming process; Friction influence; Formability limit curve.

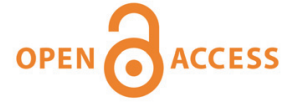

Citation: Bellini, C., Giuliano, G., Sorrentino, L., Friction Influence on the AA6060 Aluminium Alloy Formability, Frattura ed Integrità Strutturale, 49 (2019) 791-799.

Received: 02.05 .2019

Accepted: 19.06.2019

Published: 01.07.2019

Copyright: (C) 2019 This is an open access article under the terms of the CC-BY 4.0, which permits unrestricted use, distribution, and reproduction in any medium, provided the original author and source are credited.

\section{INTRODUCTION}

$\mathrm{I}$ $\mathrm{n}$ the last decades, the use of aluminium alloys has considerably grown in the automobile and aerospace industries due to its high strength-to-weight ratio and corrosion resistance [1,2]. The sheet metal stamping operation represents one of the most important processing techniques [3]. The manufacturing process design phase makes use of increasingly accurate models to evaluate the appropriate variables of the product production process. The use of software based on the finite element method (FEM) allows significant savings in time and cost, including the limitation of the onerous "trial-and-error" operations.

In [4], the authors highlighted how the material constants that characterize the behaviour of aluminium alloys can influence the results of the Erichsen test. The effect of the temperature on formability is important too; in fact, the mechanical behaviour of different aluminium alloys at "warm" process temperature was studied by Li and Ghosh [5], an increase in the flow stress with the decreasing deformation temperature was found by Lu et al. [6], while an increased formability in warm temperature condition was found by Wang et al. for AA7075 [7]. The effect of the metal microstructure on formability at high temperature was investigated by Wang et al. [8] and Rokni et al. [9]. Furthermore, the behaviour of the AA5083 and AA2017 alloys was also examined in hot pressing processes [10, 11].

The sheet propensity to undergo deformations without incurring the fracture is preserved in the design phase of a stamping process with the use of the formability limit curve (FLC). Fig. 1 shows a typical formability limit curve. It is 
represented, in terms of main strain measured in the sheet plane (maximum strain and minimum deform strain), by a graph of the necking and/or fracture conditions.

In order to ascertain the success of a sheet metal forming process, the adopted finite element code is equipped with an FLC dependent on the mechanical properties of the material. FEM verification involves a comparison between the calculated strain during the stamping process and the FLC for that material. The FLC can be derived from Hill's localized necking theory and Swift's diffuse necking one $[12,13]$. It depends on the hardening index obtainable from the results of a tensile test on the studied material.

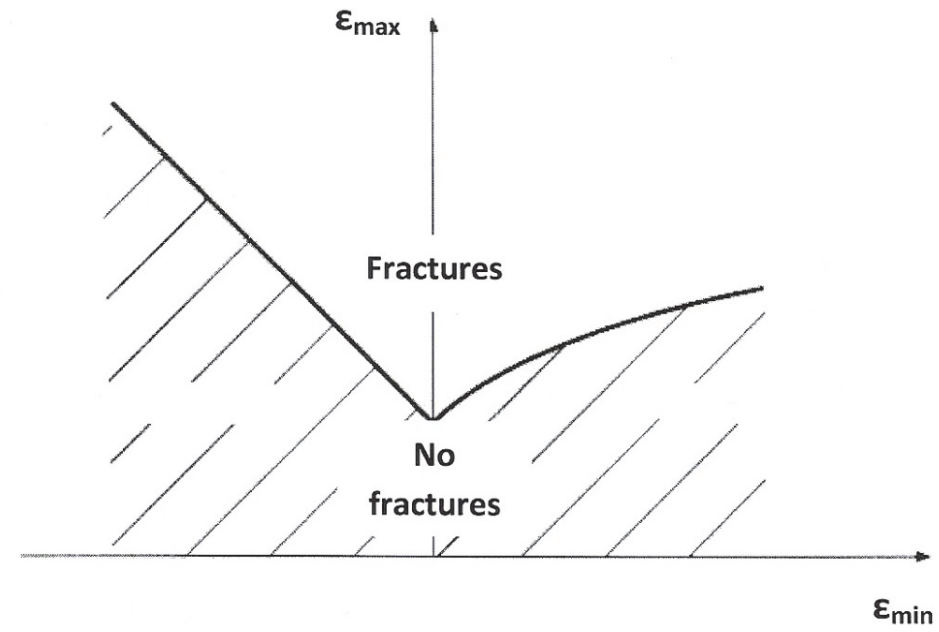

Figure 1: Typical formability limit curve of metal sheets.

$\beta$ represents the ratio between the principal strains, that are $\varepsilon_{\max }$ and $\varepsilon_{\min }$, evaluated in the sheet plane:

$$
\beta=\frac{\varepsilon_{\min }}{\varepsilon_{\max }}
$$

while the formability limit parameter can be calculated through the following relation:

$$
F L P=\frac{\varepsilon_{\max }}{F L C\left(\varepsilon_{\min }\right)}
$$

in which FLC $\left(\varepsilon_{\min }\right)$ constitutes an analytical description of the FLC as a function of the principal strain $\varepsilon_{\min }$. Therefore, on the assumption that $\beta \leq 0$, it can be stated that:

$$
\operatorname{FLC}\left(\varepsilon_{\min }\right)=\frac{n}{1+\beta}
$$

while, for $\beta>0$, it is:

$$
\operatorname{FLC}\left(\varepsilon_{\min }\right)=2 n \frac{1+\beta+\beta^{2}}{(1+\beta)\left(2=\beta+2 \beta^{2}\right)}
$$

The use of the FLP allows monitoring, by means of FEM analysis, the moment and the position in which the instability condition arises $(\mathrm{FLP}=1)$ during a plastic deformation process.

The FLC can be determined using experimental methods [14], theoretical (that is based on necking or fracture criteria of the material) $[12,13,15]$ and hybrids [16] (that is combining experimental results with analytical or numerical methods). 
Both Marciniak and Nakajima tests can be used for FLC experimental determination [17]; Banabic's work [18] examines different methods for determining the FLC.

The simplest experimental method for calculating the FLC of a sheet is the Nakazima test. This test consists in the movement, at constant speed, of a hemispherical punch against the sheet metal clamped between the die and the blank holder. The sheet is thus subjected to stretching up to the onset of the necking or fracture. To induce different deformation states in the material, the test is carried out on rectangular specimens with different width-length ratio. To detect strains on the sheet metal, a reference grid is drawn on the samples before performing the test.

In this work, adopting the FEM code and the experimental results presented in [19], the friction influence on the formability of the AA6060 aluminium alloy is highlighted. The friction effects on sheet formability are very important [20]; in fact, Yan et al. presented a scale factor to adjust the Wanheim/Bay friction model [21], Ma et al. studied the effect of temperature on the tribological behaviour in tube forming [22], Wang et al. investigated the substitution of zinc phosphate precoat with another lubricant coating [23], Hol et al. introduced a physical based model for friction simulation in fullscale modelling, taking into consideration the surface topography variation [24], Wang et al. examined the dry forming process carried out by means of a coated tool [25], Hol et al. presented an advanced friction model, based on Coulomb law, suitable for large-scale forming modelling [26], Zhang et al. studied the effect of reciprocal speed and surface roughness on the Coulomb friction coefficient through FEM simulations [27] and Wang et al. performed a study on the challenges and trends of friction analysis in sheet metal forming [28].

\section{EXPERIMENTAL ACTIVITY}

7 he material considered in this study is the aluminium-magnesium-silicon alloy named AA 6060. It is characterized by the following chemical composition by weight: $\mathrm{Al}-0.6 \% \mathrm{Si}-0.3 \% \mathrm{Fe}-0.1 \% \mathrm{Mn}-0.6 \% \mathrm{Mg}-0.1 \% \mathrm{Cu}-0.15 \% \mathrm{Zn}-$ 0:05\% Cr- $0.1 \%$ Ti.

The constitutive law of the material was determined by the tensile test according to the European standard UNI EN 10002-1. The results of the tensile test, carried out on $1 \mathrm{~mm}$ thick specimens, are reported in [19]. The material is thus characterized in the plastic field by a constitutive equation that can be expressed by the power law:

$$
\sigma=K \varepsilon^{n}
$$

where $\varepsilon$ and $\sigma$ are the equivalent strain and the equivalent stress, respectively; while $\mathrm{K}$ is the strength coefficient and $\mathrm{n}$ is the hardening index of the material.

The experimental activity involves the execution of a stamping operation performed on square-shaped specimens clamped between the die and the blank holder, both presenting a circumferential shape with a radius of approximately $83 \mathrm{~mm}$, and subjected to the action of a hemispherical punch with a radius of $60 \mathrm{~mm}$. The tests are conducted using the equipment designed at the DICeM Laboratory of the University of Cassino. This apparatus is equipped with a load cell that allows detecting the force-stroke curve of the punch. Further details on the experimental equipment are reported in [19, 29]. The tests are conducted both in the absence and in the presence of lubrication, in the latter case by using a polytetrafluoroethylene sheet (PTFE) as a lubricant between the punch and the sheet. The influence of friction on the results of the Erichsen test conducted on sheets made of different aluminium alloys and on DC05 steel was studied by the authors in $[29,30]$.

In order to determine the principal strain in the fracture conditions of the material, a grid of circles with a diameter of about $3 \mathrm{~mm}$ is drawn on the specimens before executing the forming test. The sheets are cut according to the scheme shown in Fig. 2.

\section{NUMERICAL ACTIVITY}

7 he stamping test is simulated by FEM model using the commercial calculation code MSC.Marc 2005. It consists of a trial similar to the Nakazima test considering only the geometry shown in Fig. 2. In [19] it is shown that the results of the numerical simulation conducted by means of a two-dimensional analysis (which uses axisymmetric elements) are identical to those achieved through a three-dimensional analysis, that requires shell elements, that are heavier than the axisymmetric ones. Therefore, all the results cited below refer to the lighter two-dimensional analysis.

Fig. $3 \mathrm{a}$ shows the layout of the equipment used as well as the sheet discretized with axisymmetric finite elements. 


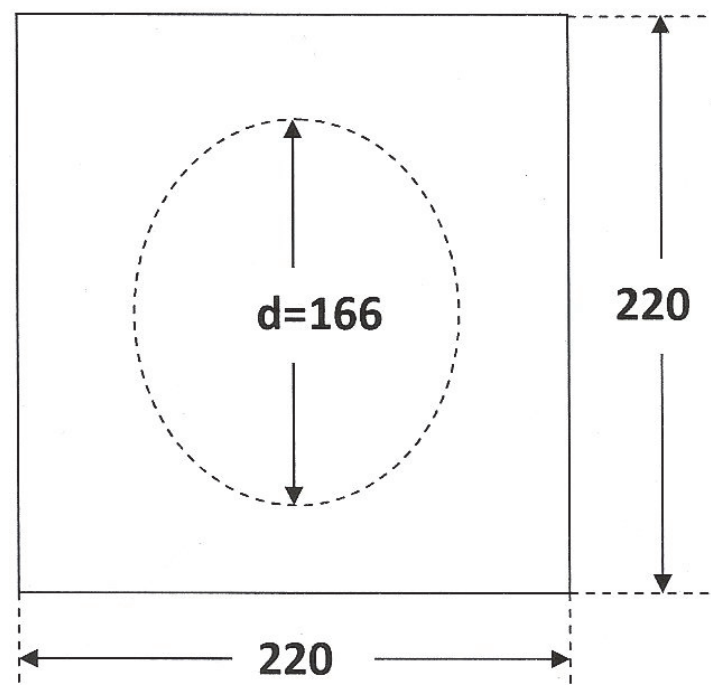

Figure 2: Geometry of the tested specimens.

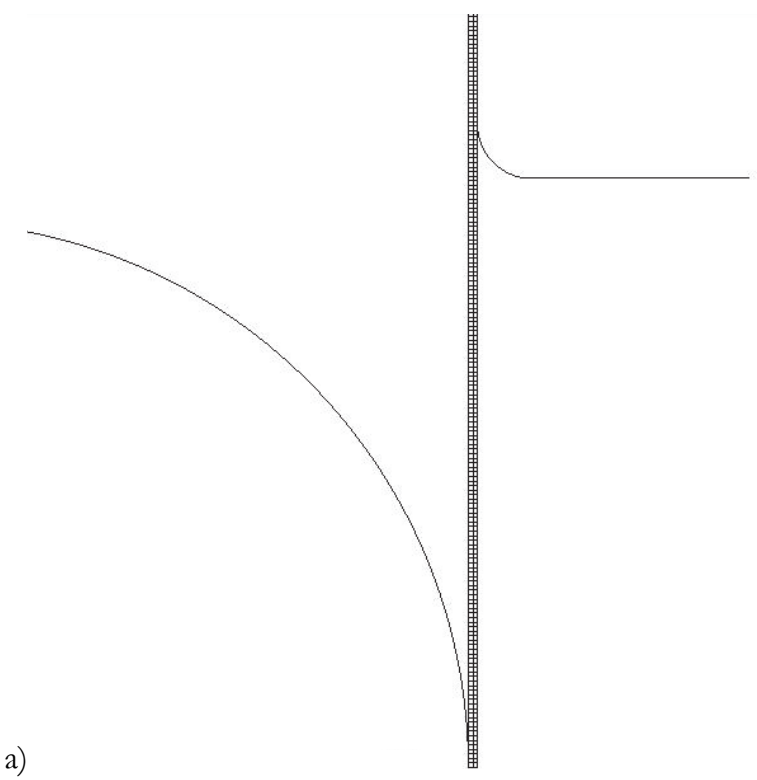

b)

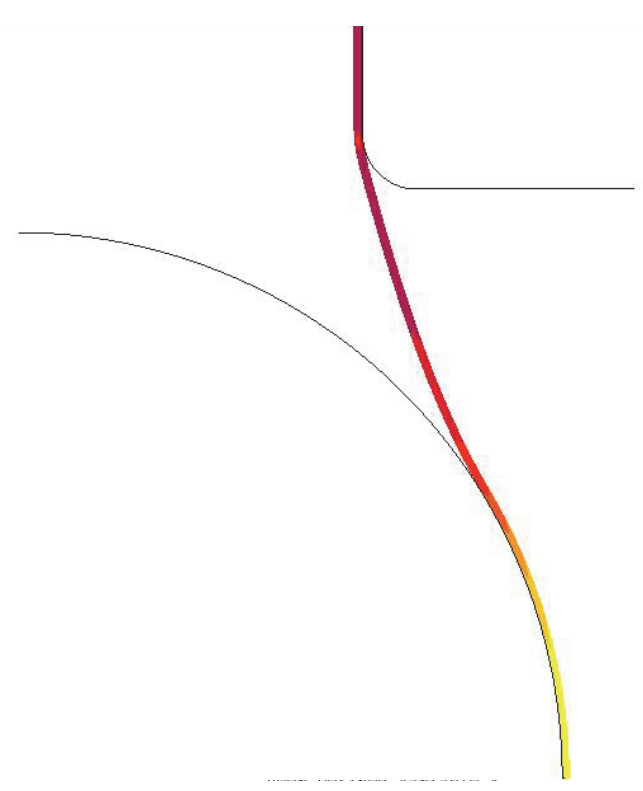

Figure 3: a) Scheme of the equipment (punch and matrix) and of the sheet metal discretized with axisymmetric finite elements; b) achievement the necking condition.

The sheet metal nodes on the outer edge are constrained to simulate the presence of the blank holder, while the nodes on the symmetry axis are not allowed to move along the direction orthogonal to the symmetry axis itself. The punch and the die are considered as rigid bodies.

To analyse the influence of the friction coefficient on the formability of the aluminium alloy AA6060, the modified Coulomb friction model is considered, whose relationship between the tangential force $f_{t}$ and the normal one $f_{n}$ is as follows:

$$
f_{t}=\mu f_{n}\left(\frac{2}{\pi}\right) \operatorname{arctg}\left(\frac{v_{r}}{\mathrm{R}_{s v}}\right)
$$


in which $\mathrm{v}_{\mathrm{r}}$ is the relative sliding speed and $\mathrm{R}_{\mathrm{sv}}$ is the relative sliding speed below which the friction force tends to vanish. The value of the friction coefficient $\mu$ varies between 0 and 0.3 . In particular, the friction coefficient assumes the values of $0,0.025,0.05,0.1,0.2$ and 0.3 .

A user-defined subroutine is used to introduce the most suitable FLC in the model.

\section{ANALYSIS OF NUMERICAL AND EXPERIMENTAL RESULTS}

7 he FEM modelling and the experimental tests conducted on the AA6060 aluminium alloy produce the following results:

1. The FLC is reached through a deformation path that varies according to the adopted friction coefficient;

2. The distance between the symmetry axis and the point where the FLP is equal to 1 decreases as the friction coefficient decreases from the value 0.1 to the value 0 , while it is almost constant for a value of the friction coefficient including between 0.1 and 0.3 ;

3. The experimental results determined in the fracture condition [19] confirm what was found in point 2;

4. The stroke of the punch (measured as the condition FLP $=1$ is reached) is maximum for a value of the friction coefficient different from zero, that is when the principal strains measured on the sheet surface are unbalanced.

Fig. $3 \mathrm{~b}$ shows, in yellow, the achievement of the instability condition (FLP $=1)$ near the sheet symmetry axis and in perfect lubrication conditions $(\mu=0)$.

In order to confirm what stated in point 1, Fig. 4 shows the deformation paths followed in the different friction conditions simulated in the work.

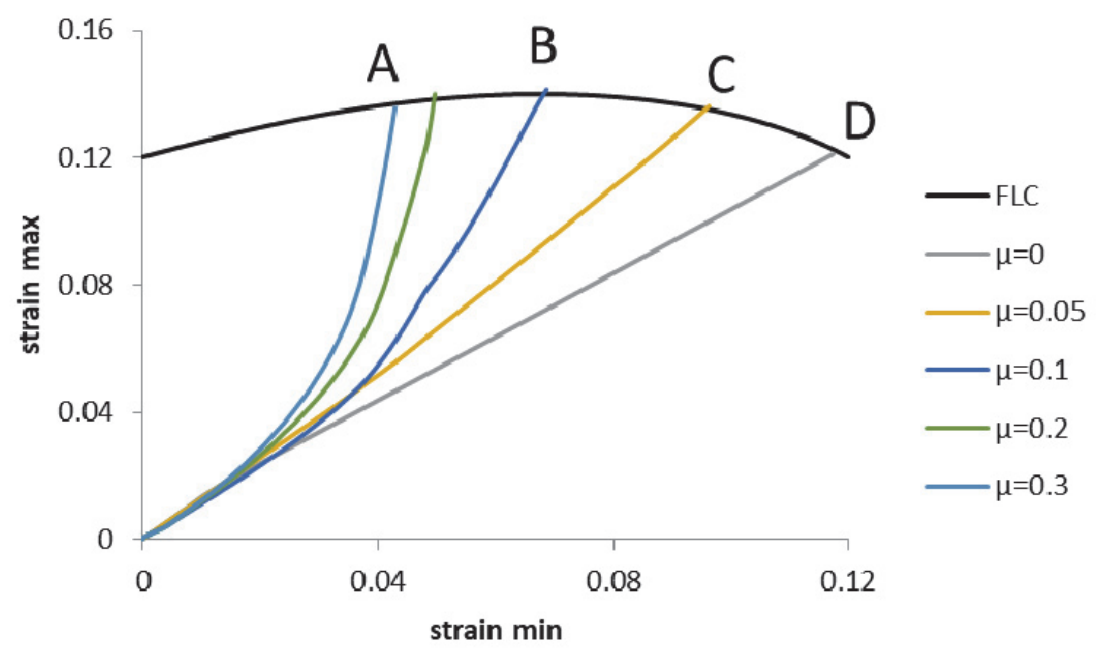

Figure 4: Deformation paths followed in different friction conditions and FLC relevant to the AA6060 aluminium alloy represented in the positive half-plane.

In Fig. 5, the achievement of the condition FLP $=1$ in the various friction conditions is observable in yellow. It is possible to point out that the yellow zone moves from the centre to the periphery of the specimen as the friction coefficient increases from 0 to 0.1 .

Fig. 6 shows the distance between the centre of the specimen and the fracture line in a sheet subjected to the experimental test conditions. In [19] it has been observed, through experimental tests, that the fracture line approaches the sheet symmetry axis if the lubrication conditions between the punch and the sheet are improved (theoretically approaching friction coefficient values equal to 0 ). Moreover, the punch stroke measured at the fracture attainment varies from about $26 \mathrm{~mm}$, in the condition of lubrication absence, to about $30 \mathrm{~mm}$, in the case a polytetrafluoroethylene sheet (PTFE) is used as a lubricant.

Fig. 7 shows the punch stroke trend, measured when the FLP $=1$ condition is reached, as a function of the friction coefficient. From the figure it is possible to highlight what stated in point 4 . This result is a direct consequence of the followed deformation path varying the friction coefficient, reported in Fig. 4. In fact, in the positive half-plane, the FLC can be represented by the curve passing through the points A-B-C-D. The A-B section of the FLC curve is characterized 
by increasing maximum and minimum strain, moving from $\mathrm{A}$ to $\mathrm{B}$ point. Therefore, in this section, the punch stroke required to reach the necking condition increases. In the B-D section, the maximum strain tends to decrease while the minimum strain increases, producing a situation in which the punch stroke increases until it reaches a maximum point (point C) and then it decreases to point D.

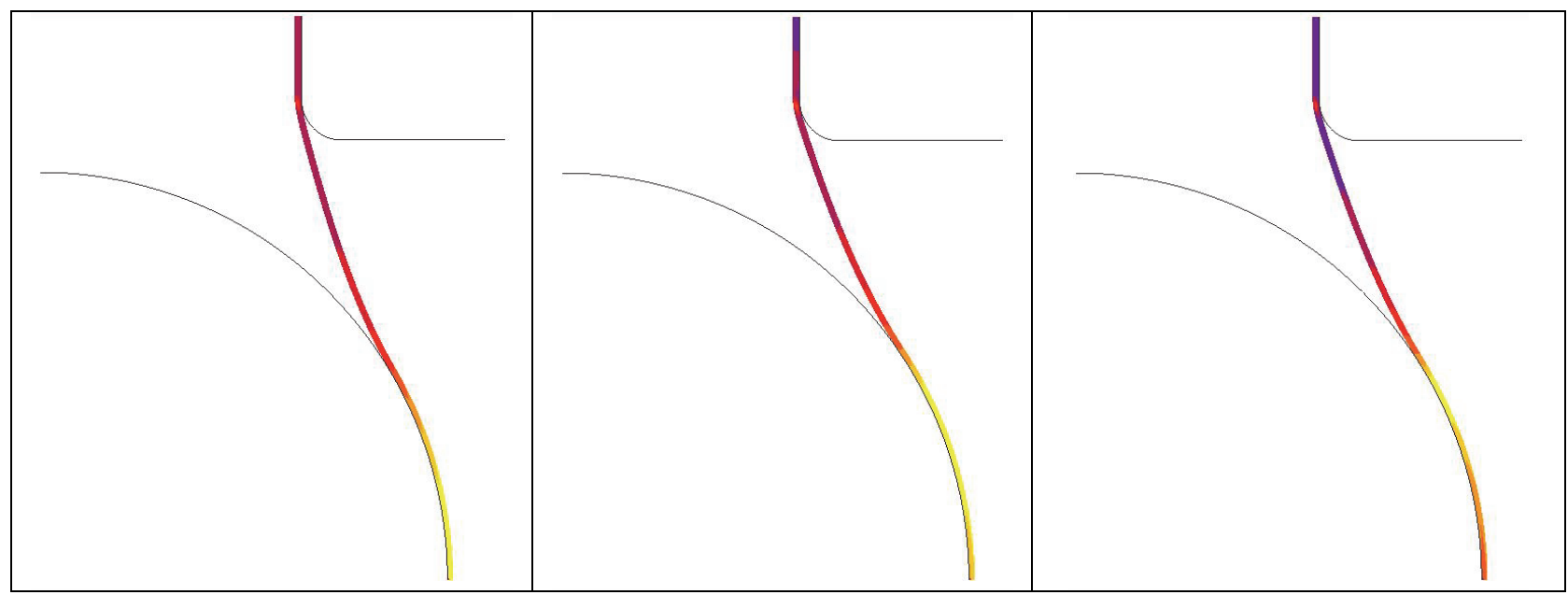

Figure 5: Achievement of the condition FLP $=1$ adopting a value of the friction coefficient equal to $0,0.05$ and 0.1 , respectively.

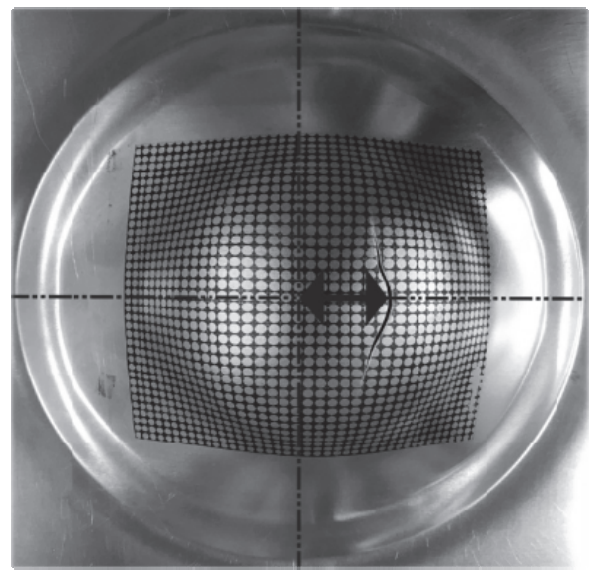

Figure 6: Photo of the specimen where the distance between the fracture line and the sheet centre is showed.

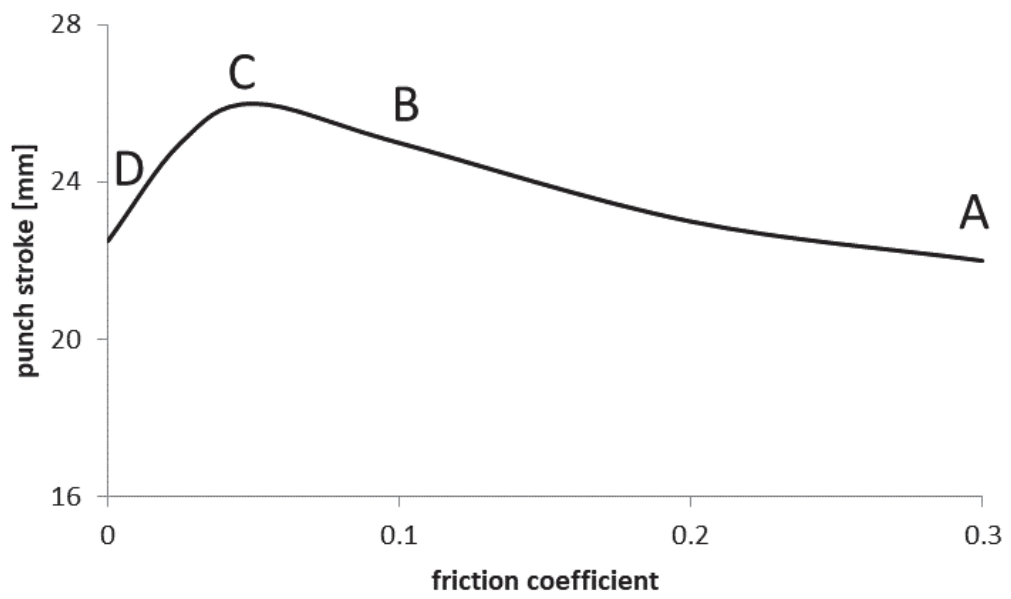

Figure 7: Punch stroke as a function of the friction coefficient. 
The FEM results of Fig. 8 highlight how the distance measured from the centre of the specimen to the point in which FLP $=1$ varies for different values of the friction coefficient. Fig. 9 shows the strain values measured in fracture conditions of the sheet tested using the polytetrafluoroethylene sheet as a lubricant.

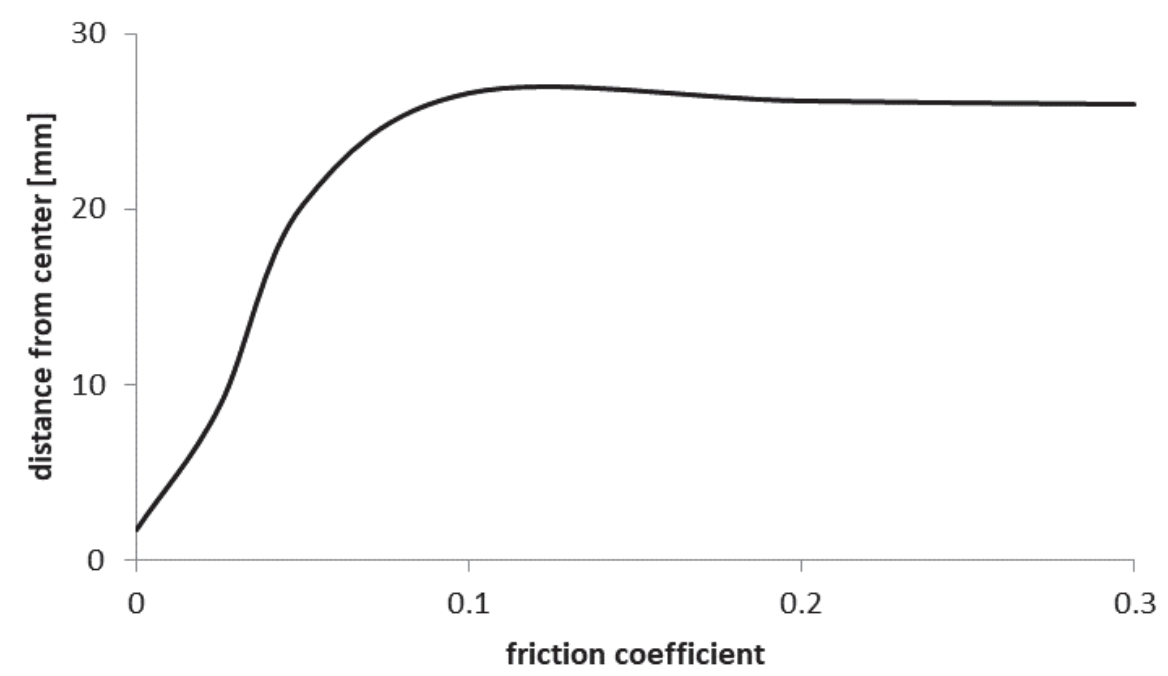

Figure 8: Distance evaluated by FEM between the FLP = 1 point and the specimen centre at the friction coefficient varying.

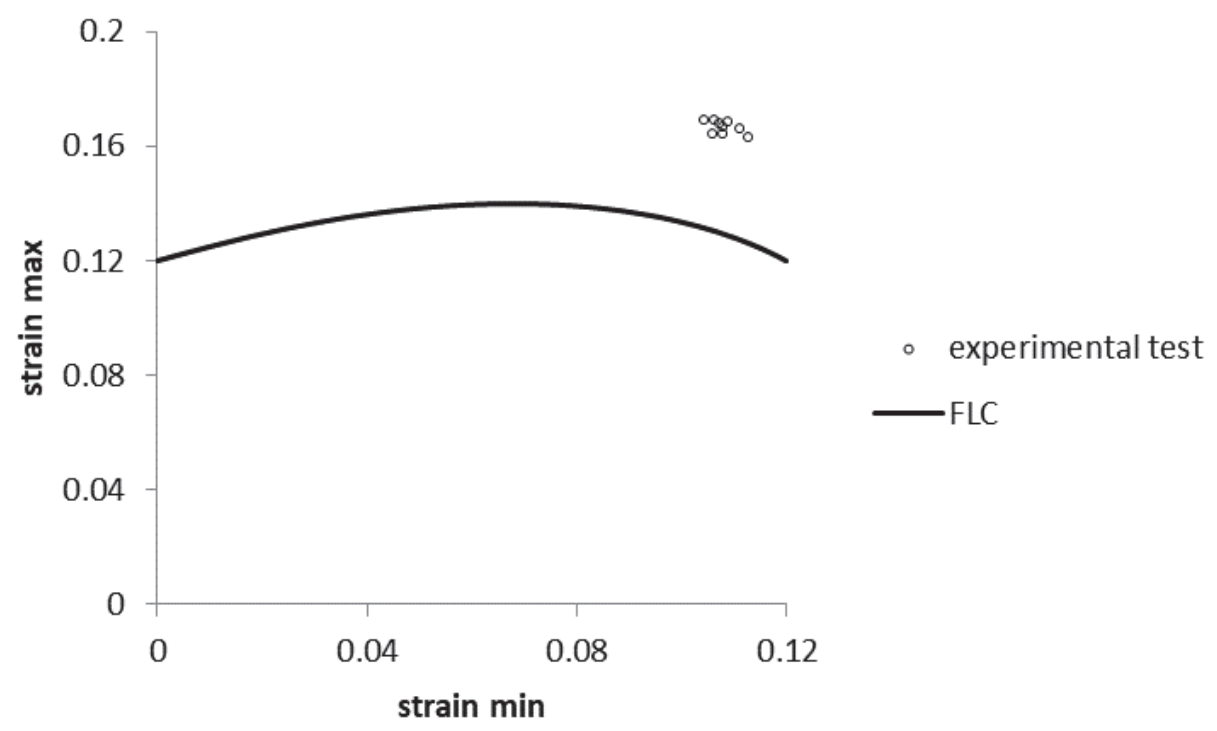

Figure 9: Strain s at break measured in experimental tests compared to the FLC of the necking condition $(\mathrm{FLP}=1)$.

\section{CONCLUSIONS}

I

$\mathrm{n}$ this work, a FEM-based two-dimensional model is chosen to analyse the friction influence on the stamping process of circular sheet metal. The sheet is modelled with the mechanical characteristics of the AA6060 aluminium alloy. In addition to the constitutive equation of the material (obtained from the tensile test), the limit formability curve (FLC) for the condition of material necking is considered. This curve depends on the hardening index of the tested material. The numerical and experimental results highlight the dependence of some characteristic parameters (such as the punch stroke, the distance between the specimen centre and the necking point) on the friction coefficient value assumed in numerical simulations. 


\section{REFERENCES}

[1] Tisza, M. and Czinege, I. (2018). Comparative study of the application of steels and aluminium in lightweight production of automotive parts. J. Light Mater. Manuf., 1(4), pp. 1-10. DOI: 10.1016/j.ijlmm.2018.09.001.

[2] Hirsch, J. (2014). Recent development in aluminium for automotive applications. T. Nonferr. Metal. Soc., 24(7), pp. 1995-2002. DOI: 10.1016/S1003-6326(14)63305-7.

[3] Rong, H.H, Hu, P., Ying, L., Hou, W., Zhang, J. (2019). Thermal forming limit diagram (TFLD) of AA7075 aluminum alloy based on a modified continuum damage model: Experimental and theoretical investigations, Int. J. Mech. Sci., 156, pp. 59-73. DOI: 10.1016/j.ijmecsci.2019.03.027.

[4] Giuliano, G. (2012). Influence of the Metal Sheet Parameters on the Results of the Erichsen Test, Appl. Mech. Mater., 217-219, pp. 2444-2447. DOI: 10.4028/www.scientific.net/AMM.217-219.2444.

[5] Li, D. and Ghosh, A. (2003). Tensile deformation behavior of aluminum alloys at warm forming temperatures, Mater. Sci. Eng. A, 352 (1-2), pp. 279-286. DOI: 10.1016/S0921-5093(02)00915-2.

[6] Lu, J., Song, Y., Hua, L., Zheng, K., Dai, D. (2018). Thermal deformation behavior and processing maps of 7075 aluminum alloy sheet based on isothermal uniaxial tensile tests, J. Alloy. Compd., 767, pp. 856-869.

DOI: 10.1016/j.jallcom.2018.07.173.

[7] Wang, H., Luo, Y., Friedman, P., Chen, M., Gao, L. (2012). Warm forming behavior of high strength aluminum alloy AA7075, T. Nonferr. Metal. Soc., 22(1), pp. 1-7. DOI: 10.1016/S1003-6326(11)61131-X.

[8] Wang, L., Strangwood, M., Balint, D., Lin, J., Dean, T.A. (2011). Formability and failure mechanisms of AA2024 under hot forming conditions, Mater. Sci. Eng. A, 528(6), pp. 2648-2656. DOI: 10.1016/j.msea.2010.11.084.

[9] Rokni, M.R., Zarei-Hanzaki, A., Roostaei, A.A., Abedi, H.R. (2011). An investigation into the hot deformation characteristics of 7075 aluminum alloy, Mater. Des., 32(4), pp. 2339-2344. DOI: 10.1016/j.matdes.2010.12.047.

[10] Giuliano, G. and Samani, F. (2016). Comparison between superplastic and non-superplastic grade AA 5083, J. Test. Eval., 44(6), pp. 2114-2119. DOI: 10.1520/JTE20150299.

[11] Giuliano, G. (2016). On the constitutive equation of AA2017 aluminium alloy at high temperature, Manuf. Lett., 10, pp. 10-13. DOI: 10.1016/j.mfglet.2016.08.003.

[12] Hill, R. (1952). On discontinuous plastic states with special reference to localized necking in thin sheets, J. Mech. Phys. Solids., 1(1), pp. 19-30. DOI: 10.1016/0022-5096(52)90003-3.

[13] Swift, H.W. (1952). Plastic instability under plane stress, J. Mech. Phys. Solids., 1(1), pp. 1-18. DOI: 10.1016/0022-5096(52)90002-1.

[14] Banabic, D., Lazarescu, L., Paraianu, L., Ciobanu, I., Nicodim, I., Comsa, D. (2013). Development of a new procedure for the experimental determination of the forming limit curves, Cirp Ann. - Manuf. Techn., 62(1), pp. 255258. DOI: 10.1016/j.cirp.2013.03.051.

[15] Marciniak, Z. (1994). Stability of plastic shells under tension with kinematic boundary condition, Arch. Mech., 17, pp. 577-592.

[16] Situ, Q., Jain, M., Metzger, D. (2011). Determination of forming limit diagrams of sheet materials with a hybrid experimental-numerical approach, Int. J. Mech. Sci., 53(4), pp. 707-719. DOI: 10.1016/j.ijmecsci.2011.06.003.

[17] Abovyan, T., Kridli, G.T., Friedman, P.A., Ayoub, G. (2015). Formability prediction of aluminum sheet alloys under isothermal forming conditions, J. Manuf. Process., 20, pp. 406-413. DOI: 10.1016/j.jmapro.2014.08.003.

[18] Banabic, D. (2010). Sheet Metal Forming Processes Constitutive Modelling and Numerical Simulation, Berlin, Springer. DOI: 10.1007/978-3-540-88113-1.

[19] Giuliano, G., Bellini, C., Sorrentino, L., Turchetta, S. (2018). Forming process analysis of an AA6060 aluminum vessel, Fract. Struct. Int., 45, pp. 164-172. DOI: 10.3221/IGF-ESIS.45.14.

[20] Nielsen, C.V. and Bay, N. (2018). Review of friction modeling in metal forming processes, J. Mater. Process. Tech., 255, pp. 234-241. DOI: 10.1016/j.jmatprotec.2017.12.023.

[21] Yan, W., Han, J., Zheng, W., Wang, G.,Wu, T. (2018). Establishment of friction model and calculation of size factor in micro/meso forming processes, Int. J. Adv. Manuf. Tech., 98 (9-12), pp. 3061-3069. DOI: $10.1007 / \mathrm{s} 00170-018-2441-8$.

[22] Ma, J., Li, H., Wang, D., Fu, M.W., Tao, Z.J. (2018). Tribological behaviors in titanium sheet and tube forming at elevated temperatures: evaluation and modeling, Int. J. Adv. Manuf. Tech., 97 (1-4), pp. 657-674. DOI: 10.1007/s00170-018-1985-y.

[23] Wang, Z.G., Komiyama, S., Yoshikawa, Y., Suzuki, T., Osakada, K. (2015). Evaluation of lubricants without zinc phosphate precoat in multi-stage cold forging, CIRP Ann.-Manuf. Techn., 64 (1), pp. 285-288.

DOI: $10.1016 /$ j.cirp.2015.04.130. 
[24] Hol, J., Meinders, V.T., De Rooij, M.B., Van Den Boogaard, A.H. (2015). Multi-scale friction modeling for sheet metal forming: the boundary lubrication regime, Tribol. Int., 81, pp. 112-128. DOI: 10.1016/j.triboint.2014.07.015.

[25] Wang, Z.G., Yoshikawa, Y., Suzuki, T., Osakada, K. (2014). Determination of friction law in dry metal forming with DLC coated tool, CIRP Ann.-Manuf. Techn., 63 (1), pp. 277-280. DOI: 10.1016/j.cirp.2014.03.050.

[26] Hol, J., Cid Alfaro, M.V., de Rooij, M.B., Meinders, T. (2012). Advanced friction modeling for sheet metal forming, Wear, 286-287, pp. 66-78. DOI: 10.1016/j.wear.2011.04.004.

[27] Zhang, S., Hodgson, P.D., Cardew-Hall, M.J., Kalyanasundaram, S. (2003). A finite element simulation of micromechanical frictional behaviour in metal forming, J. Mater. Process. Tech., 134 (1), pp. 81-91. DOI: 10.1016/S0924-0136(02)00926-3.

[28] Wang, D., Yang, H., Li, H. (2014). Advance and trend of friction study in plastic forming, T. Nonferr. Metal. Soc., 24 (5), pp. 1263-1272. DOI: 10.1016/S1003-6326(14)63188-5.

[29] Giuliano, G. (2015). Evaluation of the Coulomb friction coefficient in DC05 sheet metal forming, Stroj. Vestn.-J. Mech. E., 61(12), pp. 709-713. DOI: 10.5545/sv-jme.2015.2733.

[30] Giuliano, G. and Samani, F. (2013). Effect of lubrication on the Erichsen test, Appl. Mech. Mater., 365-366, pp. 425428. DOI: 10.4028/www.scientific.net/AMM.365-366.425. 